International Journal on Information Sciences and Computing, Vol. 5, No.1, January 2011

\title{
DEVELOP A QUALITY STRATEGY FOR RE PROCESS BY MAPPING OF SOA USING RUP
}

\author{
Priyaradhikadevi T. ${ }^{1}$, Parvathi R.M.S. ${ }^{2}$ \\ ${ }^{1}$ Research Scolar, Anna University \\ ${ }^{2}$ Research Guide, Anna University
}

\begin{abstract}
Service orientation is a new trend towards increasing the profit margins in a goal oriented organization. By using goals in requirement engineering process we have a way to achieve goals. Achieving goals require the cooperation of agents in which the services assigned. The assignment of responsibilities to agents is a critical decision in requirement engineering process. The paper describes a systematic technique to support the process of mapping of Service oriented architecture and requirement engineering activities using rational unified process which leads to successful completion of RUP software projects to provide services to their users. In this Student information system is a typical application that provides appropriate viewer for each user to assist him through services.
\end{abstract}

Keywords Requirement engineering, goals, RUP, SOA, SIS, service, mapping.

\section{INTRODUCTION}

In Requirements Engineering (RE), Goal and Actor orientation has been recognized as an approach more promising than other system- and functionality-based techniques used in most of the traditional Software Engineering methodologies. By adopting the notions of Actor, Goal, and Intentional Dependency, it is in fact possible to refine high-level requirements originating from the organizational setting (i.e., stakeholders' needs and desires) into detailed descriptions of the system to be implemented (in terms of architecture, components, and functions), in a smooth and controlled manner.

It is a powerful method that allows the analyst to model high-level organizational needs and to transform them into system requirements, while redesigning the organizational structure to better exploit the new system. The modeling effort breaks activities down into more intellectually manageable components on the basis of common conceptual notations.

The notions of Actor, Goal, and Intentional Dependency as modeling elements used throughout requirements acquisition, formalization and analysis, to capture and describe both the new system and the organizational context in which the system will operate.

By introducing service oriented architecture (SOA) on requirement engineering (RE) using Rational unified Process (RUP) to achieve both individual and organizational goals.

\section{SERVICE ORIENTED ARCHITECTURE}

SOA is an environment for dynamic invention and use of services over connected nodes in a network. SOA discipline may be used to build infrastructures finding needs and those with capabilities through services across network. A decision point for any policies and contracts that may be in force can be done in SOA [1][2]. An enterprise-scale IT architecture is called SOA which is used for linking resources on demand. These resources are made available to participants in a value net.[3].

\section{RATIONAL UNIFIED PROCESS}

RUP is a consistent methodology that supports steady development and focuses on large business projects and provides a collection of customizable techniques and practices for developing object oriented solution[4]. If proper adjustment on the design side of methodology is made, RUP can provide greater chance for SOA type application [4].

RUP is a software engineering process model, which provides a disciplined approach to assigning tasks and responsibilities within a development organization. The goal of RUP is to produce high quality software that meets the needs of its end users within a predictable schedule and budget [5]. There are two structure approaches for RUP: Static Structure, Dynamic Structure. Static structure of RUP comprise on four elements which are: Role, Activities, Artifacts, Disciplines/workflows. Dynamic structure of RUP comprises of phases and iterations in each phase: Inception, Elaboration, Construction, and Transition. 




Fig.1 RUP Activities Diagram Requirement Engineering Framework on SOA

\section{REQUIREMENT ENGINEERING ON SOA}

Requirement Engineering framework for SOA development consists of four activities such as Service Identification, Service Specification, Service Realization and Service Deployment as shown in Fig-2. Service Identification (SI), point to identification and selection of candidate services; Service Specification (SS) refers to Specification of the set of services by developing a Service Model; Service Realization (SR), refers to the designing of service component in design model and finally Service Deployment (SD refers to the transferring of the services to the production environment.

Every RUP project follows a strictly linear scheme of four phases: Inception, Elaboration, Construction and Transition. Each of these phases, except for inception, encompasses all the activities service identification, service specification and service realization. During the inception phase, emphasis is given to determine the scope of project not in term of services. In normal development of RUP project, inception is considered as core phase to understand the whole concept but in SOA methodology inception can be namely as a part of the Service realization activity [6]

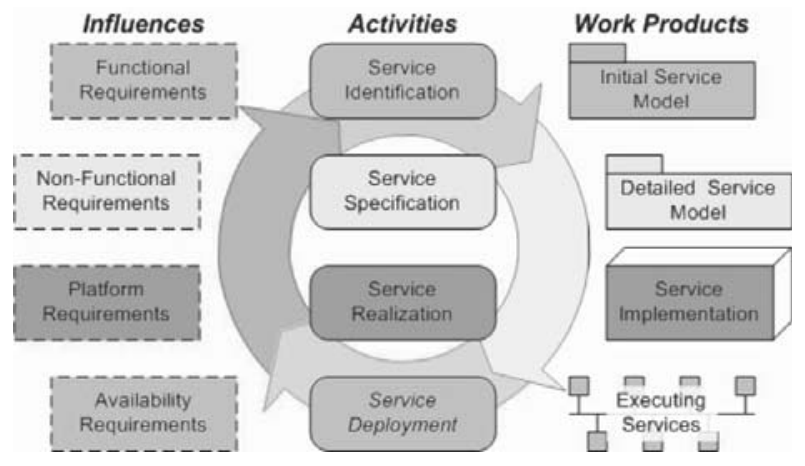

Fig. 2 The RE-SOA framework
Every RUP project follows a strictly linear scheme of four phases: Inception, Elaboration, Construction and Transition. Each of these phases, except for inception, encompasses all the activities service identification, service specification and service realization. During the inception phase, emphasis is given to determine the scope of project not in term of services. In normal development of RUP project, inception is considered as core phase to understand the whole concept but in SOA methodology inception can be namely as a part of the Service realization activity [6].

\section{MAPPING STRATEGY: SIS}

SIS means to Student Information Systems to provide in a more efficient way of interaction between student and staff. SIS is a particularly interesting and challenging sector for $R E$, in which it is relevant to adopt a methodology capable of taking into account different services, their points of view, and the resulting strategic dependencies. In this context, in fact, very diverse kinds of services are involved, each of them with its objectives and goals. Some goals may be quite straightforward (as, e.g., for viewing academic performance to knew the circular), others rather complex and articulated (as, e.g., for an administrator, to be compliant to laws and norms), and sometimes they may diverge quite considerably.

For example, to know the details about the student they must enter into admin using their login and they have to access. The admin will verify the user name and password to provide access rights to the student and make them to read and not to write. Thus, in general, SIS applications have to operate in a intranet environment characterized by a rich tissue of actors with strong inter-dependent intents. Due to this complex network of interrelated objectives, synergies and convicts may be present. Being able to clearly identify the set of involved actors, their objectives (i.e., goals), and the way they depends on each other in order to achieve such goals, most likely by exploiting possible synergies or trying to avoid potential convicts, is of utmost importance to obtain a clear and complete comprehension of the organizational setting into which the new technology should be introduced. And only from such a deep comprehension of the application context the correct system requirements can be derived, and, consequently, the correct system can be designed and implemented. 
Thus, a RE methodology satisfying this perspective must be capable of describing both the requirements of the system and its social context. These descriptions must share a common notation, in order to be able to strictly connect the system requirements to the real organizational needs the organization has, and to easily evaluate the possible impact the system may have on the way of acting of the organization and its actors. Mapping of RE by applying SOA tries to provide such a capability by adopting a diagrammatic notation for describing the organizational settings: this notation immediately conveys the intentional dependencies among the different actors, and allows for a detailed analysis of the goals upon which the actors depend, through a goal decomposition process. Moreover, the notation is used to describe not only the organizational setting but also the system itself, as an (artificial) actor placed in the context of the organization.

Moreover, REF introduces also a clear methodology to drive the process of requirements discovery, definition, refinement and reconciliation

Another important simplification is introduced by imposing a strict top-down approach to the process of goal analysis. These choices, although apparently constraining, results to be quite successful in practical terms. Several case studies demonstrate, in fact, that the simplified notation and process facilitates the acceptance of this mapping strategy RE on SOA using RUP by us, and contributes to a quicker introduction of the methodology in the RE process.

A distinction is made in mapping $R E$ between soft and hard goals. Soft-goals are used to specify, at a qualitative level, not sharply-cut objectives, the precise definition of which requires developing further details, while hard-goals clearly define a state/target, an actor desires to reach.

The tests of services with classification are provided by SIS.

The student information system which consists of masters, admin, student and staff based information system in which it is fully automated one and no manual work in this system.

The purpose of this system is to gain more information regards to department level and in student level to the student and to the staff.

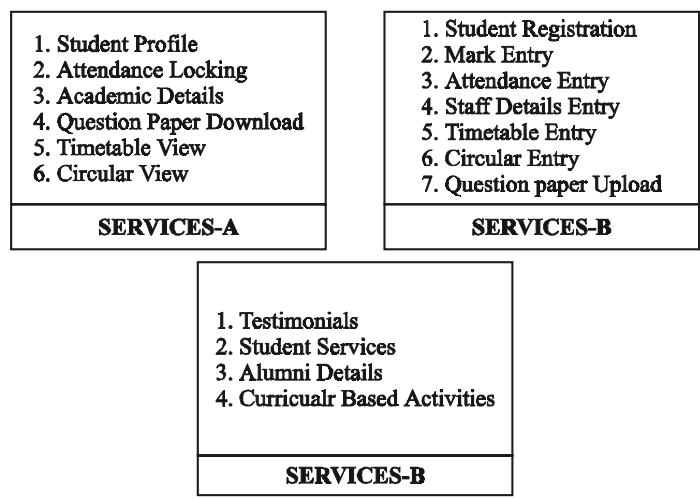

Fig. 3 SIS services with classification

The staff can easily pass over all the information about the student via this login and the particular student can view it by entering into his login by giving pass word. It solves security ability by providing pass security to staff based student based.

The staff can easily pass over the student absence in class by just entering his name and the information is passing over to their parents contact number. If person wants to get permission for leave also they can send a requisition letter to their class advisor and if ok means it pass over to HOD and then to student.

The circular module which includes how long the message has to be scroll in the home page is mentioned by giving the start and the end date. The student can easily know all the general information from the home page itself.

When we considering the concepts of staff information it just contain a database about the staff and it is accessible only to the staff level. It also contain the general information about their exam duty, time table and subject which he/she handling.

The student information which also contains information based on extra curricular activities of each student and their interesting and stored as a database in this information system. It is based on placement activities, exam scorer and sports etc..,

SIS which reports the information based on the class wise, student wise or subject wise as a graph or chart to know the performance by comparing with others It is developed for full and fully to reduce the manual work in department level and it act as a complete view of database based on student information. It contains all the information about the 
student and we can view the particular person full details by just entering their name or their unique id.

The overall dig-4 which shows the full data flow of content between the actors and admin.



Fig. 4 Overall Dataflow on RE

Order the list of goals from high-level concern to low-level concern

- Admin receives a request for a attendance from a system for a student and report it.

- Collect student data base by system.

- Schedule timetables for staff.

- System collects timetables from user.

- Report for the entire request.

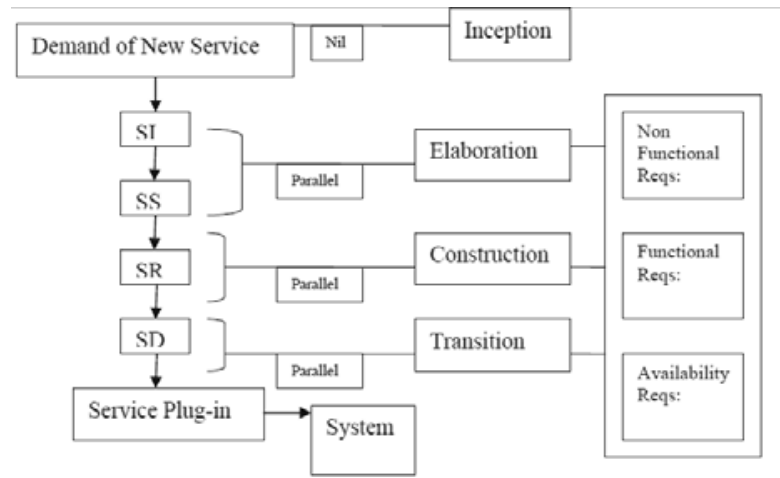

Fig. 5 shows the mapping of SOA and RE activities using Rational Unified Process

After studying RUP and RE frame work, we observe that RUP phases can involved many activities work of RE framework. During elaboration phase of RUP, services of SIS are identified which are shown in Table.
Table-1 Identification of SIS services

\begin{tabular}{|c|c|c|}
\hline Services & $\begin{array}{l}\text { Influence Functional } \\
\text { Req: } \\
\text { Non-Functional Req: }\end{array}$ & $\begin{array}{l}\text { Couple } \\
\text { Service }\end{array}$ \\
\hline \multirow[t]{2}{*}{ Services-A } & Appropriate Viewer & $\begin{array}{l}\text { Depends on } \\
\text { Admin } \\
\text { activities }\end{array}$ \\
\hline & $\begin{array}{l}\text { Product, Organizational } \\
\text { and external } \\
\text { requirements }\end{array}$ & \\
\hline \multirow[t]{2}{*}{ Services-B } & Appropriate Viewer & $\begin{array}{l}\mathrm{B} 1 \rightarrow \mathrm{A3} \\
B 2 \rightarrow A 6, B 10 \\
B 3 \rightarrow A 4 \\
B 4 \rightarrow A 5\end{array}$ \\
\hline & $\begin{array}{l}\text { Product and } \\
\text { Organizational } \\
\text { requirements }\end{array}$ & \\
\hline \multirow[t]{2}{*}{ Services-C } & Appropriate Viewer & $\begin{array}{l}\text { C1 to } \\
C 9 \rightarrow A-1\end{array}$ \\
\hline & $\begin{array}{l}\text { Product, Organizational } \\
\text { and external } \\
\text { requirements }\end{array}$ & \\
\hline \multicolumn{3}{|c|}{$\begin{array}{l}\text { The service model is the outcome of SOA } \\
\text { activities which shows the specification of service by } \\
\text { defining input, output and relevant operations. The } \\
\text { service model for specification of SIS services is shown } \\
\text { in Table-2 }\end{array}$} \\
\hline
\end{tabular}

Table-2 Service Model for SIS

\begin{tabular}{|l|l|l|}
\hline SERVICES & \multicolumn{1}{|c|}{ INPUT } & \multicolumn{1}{c|}{ OUTPUT } \\
\hline Student & User ID & $\begin{array}{l}\text { Any student can } \\
\text { view their } \\
\text { own profile and } \\
\text { their academic } \\
\text { \& attendance } \\
\text { details }\end{array}$ \\
\cline { 2 - 2 } & QP download & \\
\cline { 2 - 3 } & Academic & \\
\cline { 2 - 3 } & Performance & \\
\cline { 2 - 3 } & Time table & \\
\hline
\end{tabular}




\begin{tabular}{|c|c|c|}
\hline SERVICES & INPUT & OUTPUT \\
\hline \multirow[t]{6}{*}{ Staff } & User ID & \multirow{6}{*}{$\begin{array}{l}\text { Any staff can } \\
\text { modify / update } \\
\text { student details } \\
\text { and authority is } \\
\text { given based on } \\
\text { cadre. }\end{array}$} \\
\hline & Student Registration & \\
\hline & Mark entry & \\
\hline & Circular Entry & \\
\hline & Upload & \\
\hline & Staff Details & \\
\hline
\end{tabular}

\section{CONCLUSION}

The software industry is more than ever facing a challenge of delivering WYGIWYW software (What You Get Is What You Want) software. A well structured technique specifying adequate, complete, consistent, precise and measurable requirements are essential for solves the problem. Our proposed approach, a mapping strategy of SOA and RE activities and improve the services in goal oriented organization.

\section{REFERENCES}

[1] Shahid Hussain: Role Communication Model in RUP: Using Pair Programming Concepts, 2008

[2] Hans Admiraal: SOA gains importance to the RUP,(2008)

[3] Papazoglou et al.: "Service Oriented Computing Roadmap" Dagstuhl Seminar Proceedings. 005462. Service Oriented Computing (SOC). (2006).

[4] Hans Admiraal, "SOA gains importance to the RUP" , Hans Admiraal, 2008.
[5] Philippe Kruchten, "The Rational Unified Process An Introduction, Second Edition", 2000.

[6] David West, "Planning a Project with the Rational Unified Process", 2002.

[7] Shahid Hussain and Fida Hussain, "Role Communication Model in RUP: Using Pair Programming Concepts", NCICT, 2007.

[8] Guillermo A. Callahan, "Suitability ofExtreme Programming and RUP Software Development Methodologies for SOA Applications", 2006.

[9] Mohamad Afshar, "SOA Governance: Framework and Best Practices", An Oracle White Paper, 2007.

[10] Qusay H. Mahmoud: Service-Oriented Architecture(SOA) and Web Services: The Road to EnterpriseApplication Integration (EAI), April(2006)

[11] Partl - Understanding SOA: Excerpted with permission from Applied SOA: Service-Oriented Architecture and Design Strategies. (Page 78 -98)

[12] Ali Arsanjani, Ph.: Service-oriented modeling and architecture, Nov (2004)

[13] Guillermo A. Callahan: Suitability of Extreme Programming and RUP Software Development Methodologies for SOA Applications,( 2006).

[14] Formal Methods for Software Architectures, Tutorial book on software architectures and formal methods, M. Bernardo and P. Inverardi, eds. Springer, 2003.

[15] J. Aldrich, "Using Types to Enforce Architectural Structure," Proc. Working IEEE/Int'l Federation for Information Processing (IFIP) Conf. Software Architecture, pp. 211-220, 2008. 